\title{
An Evidence-Informed Model of Care for People with Lower Limb Osteoarthritis in New Zealand
}

Daniel W. O'Brien PhD

Senior Lecturer, Department of Physiotherapy, School of Clinical Sciences, Auckland University of Technology, Auckland, New Zealand; Active Living and Rehabilitation: Aotearoa New Zealand, Health and Rehabilitation Research Institute, School of Clinical Sciences, Auckland University of Technology, Auckland, New Zealand

Wesley Pigg BHSC (Physiotherapy)

Staff Physiotherapist, North Shore Hospital, Waitematā District Health Board, Auckland

\section{Richard Ellis PhD}

Associate Professor, Department of Physiotherapy, School of Clinical Sciences, Auckland University of Technology, Auckland, New Zealand; Active Living and Rehabilitation: Aotearoa New Zealand, Health and Rehabilitation Research Institute, School of Clinical Sciences, Auckland University of Technology, Auckland, New Zealand

Jennifer N. Baldwin PhD

Research Officer, Priority Research Centre in Physical Activity \& Nutrition, Faculty of Health and Medicine, The University of Newcastle, Australia

Jonathan G. Quicke PhD

Academic Clinical Lecturer, Primary Care Centre Versus Arthritis, Research Institute for Primary Care and Health Sciences, Keele University, Keele, United Kingdom

Nicola Evans BSC (Hons)

Impact Accelerator Unit Projects Manager, Primary Care Centre Versus Arthritis, Research Institute for Primary Care and Health Sciences, Keele University, Keele, United Kingdom

\section{Krysia Dziedzic PhD}

Professor, Primary Care Centre Versus Arthritis, Research Institute for Primary Care and Health Sciences, Keele University, Keele, United Kingdom

\section{ABSTRACT}

Osteoarthritis (OA) is a prevalent and costly condition. Evidence-based clinical guidelines recommend three core treatments for OA: education, exercise, and weight loss (as appropriate). However, the translation of evidence into practice is limited. Clinical guidelines do not provide information on how to implement recommendations in local care settings. In New Zealand, management of people with OA in primary care is inconsistent and fragmented. Clinicians and researchers have made a call for a New Zealand OA model of care to close this evidence-practice gap and optimise primary care OA management nationwide. A model of care is a conditionspecific implementation strategy that outlines what care should be funded and delivered, who should provide it, and where and how care should be addressed. Various models of care for OA have been implemented with promising results in Australia, the United Kingdom (UK) and Europe. One programme that is translating guidelines into practice is the Model OsteoArthritis Consultation (MOAC). Empirical evaluations of the MOAC in the UK and Europe have demonstrated greater delivery of core treatments, better service quality, and improved patient outcomes. This article makes a case for piloting the MOAC in New Zealand as an implementation strategy to optimise primary care management of OA.

O’Brien, D. W., Pigg, W., Ellis, R., Baldwin, J. N., Quicke, J. G., Evans, N. \& Dziedzic, K. (2021). An evidence-informed model of care for people with lower limb osteoarthritis in New Zealand. New Zealand Journal of Physiotherapy, 49(1), 24-30. https://doi.org/10.15619/NZJP/49.1.04

Key Words: Osteoarthritis, Model of Care, New Zealand

\section{BACKGROUND: THE CURRENT IMPACT OF OSTEOARTHRITIS IN NEW ZEALAND}

Osteoarthritis $(\mathrm{OA})$ is a common musculoskeletal disorder that affects 303.1 million people globally, accounting for 9.6 million years lost due to disability (James et al., 2018). In New Zealand, approximately $10 \%(386,000)$ of adults live with OA (Ministry of
Health, 2017). Population ageing means the prevalence of OA in New Zealand is expected to rise to $12.7 \%$ by 2040 (Arthritis New Zealand, 2018). OA is associated with considerable cost to the economy. It was estimated that arthritis (of which OA is the most common form) cost New Zealand $\$ 12.2$ billion in 2018 , including $\$ 7.9$ billion in lost well-being, $\$ 3.3$ billion in lost productivity, and $\$ 993$ million in health sector costs 
(Arthritis New Zealand, 2018). Furthermore, the healthcare costs of knee OA in New Zealand are projected to increase from $\$ 199$ million in 2013 to $\$ 370$ million in 2038 (Wilson \& Abbott, 2019). Total hip joint replacements and total knee joint replacements for $\mathrm{OA}$ are increasing throughout the developed world, including in New Zealand. By 2026, the number of total hip joint replacements and knee joint replacements performed per year in New Zealand is predicted to increase by $84 \%$ and $183 \%$, respectively (Hooper et al., 2014). These are concerning projections considering the high cost of such surgeries.

Furthermore, this growing cost highlights the importance of exhausting all non-surgical treatment approaches (i.e., education, exercise, and weight loss) to improve outcomes and potentially reduce the need for surgery (Allen, Bongiorni, et al., 2016).

\section{Table 1}

National Institute for Health and Clinical Excellence Recommendations for Osteoarthritis Treatment

Core osteoarthritis treatment recommendations for all individuals

Education and selfmanagement

Referral for consideration of joint surgery

Follow-up and review

\section{EVIDENCE-PRACTICE GAP}

Various international evidence-based guidelines exist to inform the management of OA. For example, the National Institute for Health and Care Excellence (NICE) guideline for OA care and management was developed based on the best available evidence and consultation with key stakeholders (National Institute for Health and Care Excellence [NICE], 2021). The NICE standards recommend that treatment emphasises selfmanagement and is progressive depending on the person's needs, and that all people with OA should receive three core treatments: education, exercise, and weight loss interventions (as appropriate) (Table 1) (NICE, 2021).

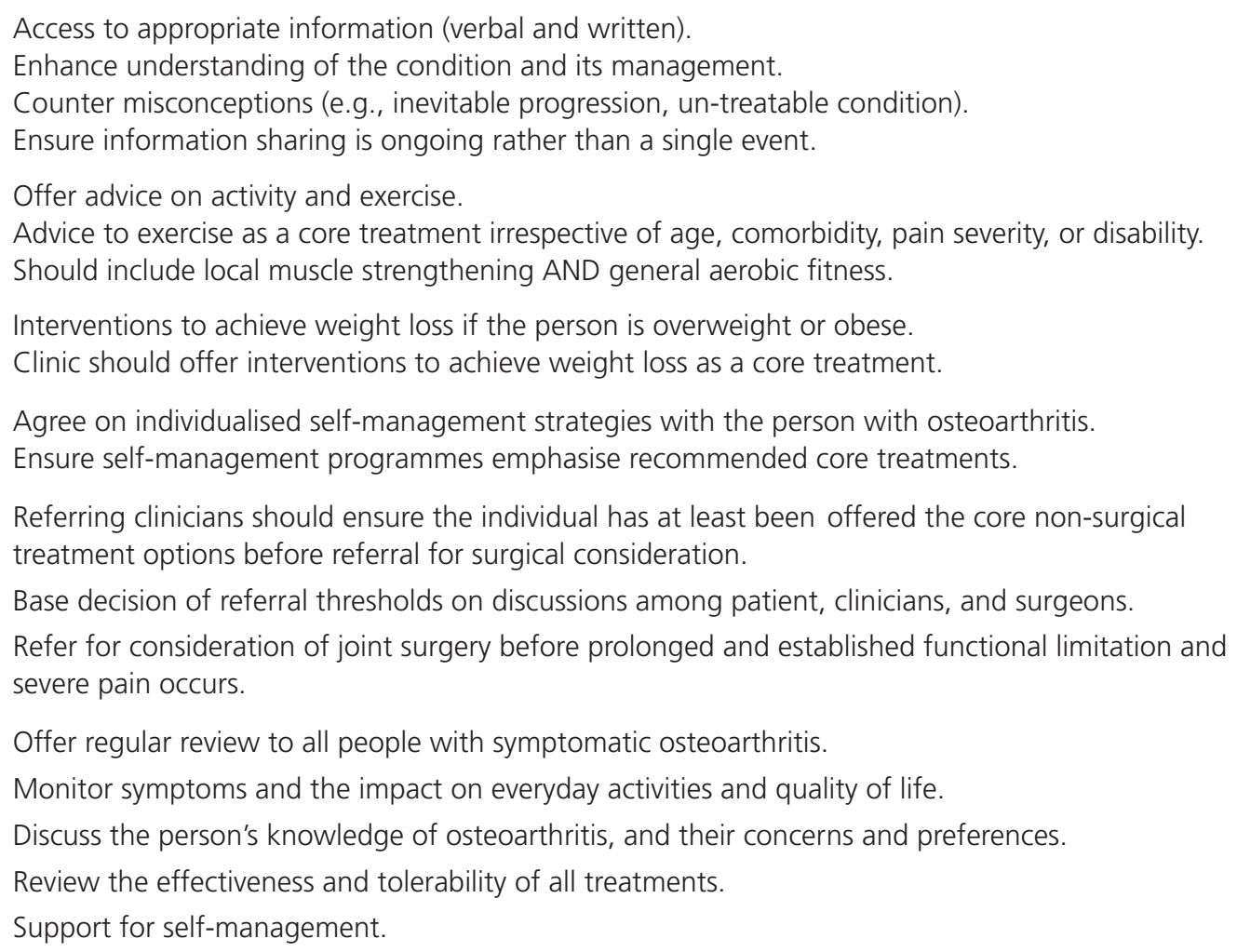

Agree on individualised self-management strategies with the person with osteoarthritis. Ensure self-management programmes emphasise recommended core treatments.

Referring clinicians should ensure the individual has at least been offered the core non-surgical treatment options before referral for surgical consideration.

Base decision of referral thresholds on discussions among patient, clinicians, and surgeons.

Refer for consideration of joint surgery before prolonged and established functional limitation and severe pain occurs.

Offer regular review to all people with symptomatic osteoarthritis.

Monitor symptoms and the impact on everyday activities and quality of life.

Discuss the person's knowledge of osteoarthritis, and their concerns and preferences.

Review the effectiveness and tolerability of all treatments.

Support for self-management.

Note. Recommendations adapted from Conaghan et al. (2008).

Despite the robust evidence upon which these guidelines are based, research shows a gap between guideline recommendations and the clinical management of $\mathrm{OA}$, both in New Zealand and internationally (Abbott et al., 2019; Brand et al., 2011; Poitras et al., 2010). In New Zealand, most people with OA first consult their general practitioner (GP) regarding their condition. However, research suggests that recommended treatments following this initial GP visit are inconsistent (Jolly et al., 2017; Larmer et al., 2019). Evidence from the United Kingdom (UK) and Europe also demonstrates limited uptake of clinical guidelines in practice, especially guidelines concerning non-surgical and non-pharmacological treatments for OA
(Healey et al., 2018; Porcheret et al., 2013). In light of this evidence-practice gap, a paradigm shift is needed to optimise non-pharmacological management and delay (or avoid) surgical intervention (Allen, Bongiorni, et al., 2016; Hunter, 2011, 2017).

\section{ASSESSMENT OF THE PROBLEM: DOES NEW ZEALAND NEED A MODEL OF CARE FOR OA?}

In New Zealand, management of OA in primary care is fragmented, and no clear implementation strategy exists to translate guidelines into clinical practice (Baldwin et al., 2017; Jolly et al., 2017; Reid et al., 2014). Community Health Pathways is a New Zealand online resource available primarily to 
GPs to plan patient care (Goddard-Nash et al., 2020; McGeoch et al., 2015). Still, it is unclear to what extent these pathways influence clinical practice. A call has been made by primary care clinicians and researchers for the development of a New Zealand model of care for OA (Baldwin et al., 2017). A model of care is a condition-specific management pathway that aims to close the gap between guideline recommendations and clinical management (Briggs et al., 2016). A critical limitation of clinical practice guidelines is that they fail to provide information on implementing valuable evidence-based recommendations in clinical practice. A model of care addresses what care should be delivered, who should deliver it, where it should be delivered, and how it should be delivered (Allen, Bongiorni, et al., 2016).

New Zealand has a unique funding arrangement involving the Accident Compensation Corporation/Te Kaporeihana āwhina Hunga Whara (ACC) that only covers accident-induced injuries. ACC also provides significant funding for the care of New Zealanders with accident-induced injuries (Accident Compensation Corporation/Te Kaporeihana āwhina Hunga Whara, 2020). Still, it presents a challenge for managing chronic conditions such as OA, as care for these conditions is not typically covered by ACC, as often they do not meet the funding criteria of being caused by an accident. Between 2015 and 2019, the New Zealand Ministry of Health established the Mobility Action Programme (MAP), with the specific purpose of developing clinical services for people living with chronic musculoskeletal conditions (Ministry of Health, 2019). The MAP was designed to fund a range of community-based, multidisciplinary programmes aimed at improving primary care management of musculoskeletal conditions. The broader aim of the MAP was to identify service delivery models that provide the greatest benefits for people with musculoskeletal disorders, while also providing value for money in terms of resources invested (Ministry of Health, 2019). Anecdotally, the MAP has supported several successful projects, but the final project analysis report is yet to be released by the Ministry of Health.

\section{LOOKING INTERNATIONALLY FOR AN OA MODEL OF CARE FOR NEW ZEALAND}

Models of care for OA have been implemented in the UK, Europe, and Australia, hence it is appropriate to examine these international examples when considering what a New Zealand OA model of care could look like (Allen, Choong, et al., 2016; Briggs et al., 2014; Dziedzic et al., 2018). The Model OsteoArthritis Consultation (MOAC) is an example of an implementation strategy applied and robustly evaluated in the UK, delivering promising preliminary results (Quicke et al., 2019). The MOAC aims to achieve the core recommendations from the NICE guidelines in primary care. The programme focuses on supporting self-management for people with OA, with enhanced linkages among health professionals involved in delivering care. Figure 1 presents an example of a MOAC-based clinical pathway for a person with $\mathrm{OA}$.

Several large projects across the UK and Europe have evaluated the effectiveness of the MOAC in terms of OA outcomes and the uptake of the NICE core recommendations (Figure 2) (Keele University, n.d.). In these projects, elements of the MOAC were adapted to the local context; namely, the healthcare professionals involved in delivering the service, the setting, service buy-in, and staff availability.

The Managing OSteoArthritis In ConsultationS (MOSAICS) study was a large, robust cluster randomised controlled trial conducted in the UK (Dziedzic et al., 2018). The trial involved 525 participants with OA across eight general practices. In the MOSAICS study, implementation of the MOAC followed several key steps that promoted the core treatments outlined in the NICE guidelines (Dziedzic et al., 2018). In particular, the MOSAICS study used four care innovations:

- the MOAC (Figure 1);

- an OA guidebook (co-designed with patients and the public);

- recording OA care quality in an electronic medical records template matched against the NICE guidelines;

- training for healthcare staff (GPs, practice nurses, and physiotherapists).

In addition to the MOSAICS study, the MOAC was recently implemented and evaluated in two further studies: the Joint Implementation of Osteoarthritis Guidelines in the West Midlands (JIGSAW) in the UK, and a European version (JIGSAW-E), which is being piloted across Western Europe (Keele University, n.d.). The JIGSAW-E study involved the systematic implementation of previously tested innovations from the JIGSAW project in five European regions (the UK, the Netherlands, Norway, Denmark, and Portugal). The JIGSAW and JIGSAW-E studies adopted the same MOAC principles, emphasising self-management and integrated primary care. For example, the JIGSAW and JIGSAW-E projects indicated care could be delivered by a GP and practice nurse, or by other staff (e.g., physiotherapists, healthy lifestyle advisors, or pharmacists) working alongside GPS. The JIGSAW and JIGSAW-E projects also demonstrated that the fundamental MOAC principles could be pragmatically and flexibly implemented in different healthcare settings to improve care quality for people with OA.

Evaluation of the MOAC in the MOSAICS, JIGSAW and JIGSAW-E studies has yielded promising results. Implementation of the MOAC increased the delivery of core treatments recommended in the NICE guidelines; namely, increased written and verbal information on $\mathrm{OA}$ and advice regarding exercise, as well as greater prescription of strengthening exercises (Dziedzic et al., 2018; Healey et al., 2018; Porcheret et al., 2018). The MOAC also led to an increase in the diagnosis of "OA" rather than "joint pain", more frequent recording of a patient's weight, an increased number of physiotherapy referrals, a decrease in the reliance on radiographs for assessment and diagnosis, and a reduction in the use of oral nonsteroidal anti-inflammatory drugs and walking aids by people with OA (Jordan et al., 2017).

Qualitative assessment of the MOAC showed that it was considered acceptable by GPs, nurses, and people with OA (Morden et al., 2014; Porcheret et al., 2018). GP attendance at MOAC training workshops resulted in improved consulting behaviour and a self-reported shift in the perception of OA from being an untreatable condition to one where effective conservative treatments are available (Morden et al., 2015; 


\section{Figure 1}

Example Patient Pathway Based on the Model OsteoArthritis Consultation

1. Patient aged 45 years or older presents with joint pain

2. General practitioner consultation

- Clinical diagnosis of osteoarthritis (OA) made with explanation

- Support for self management (e.g. the OA guidebook)

- National Institute for Health and Care Excellence core treatments promoted

- Follow-up consultation booked with designated health professional in 2-4 weeks

3. Follow -up with designated health professional (e.g. physiotherapist, practice nurse)

- Self-management supported, including use of OA guidebook

- Answer questions and clarify concerns, review self-management plan

- Focus on exercise/physical activity, weight loss, pain control

- Agree on goals and review two times over 6 weeks

\section{Figure 2}

Linked Series of Projects from Initial Research Through Local Implementation of Innovations to International Pilots

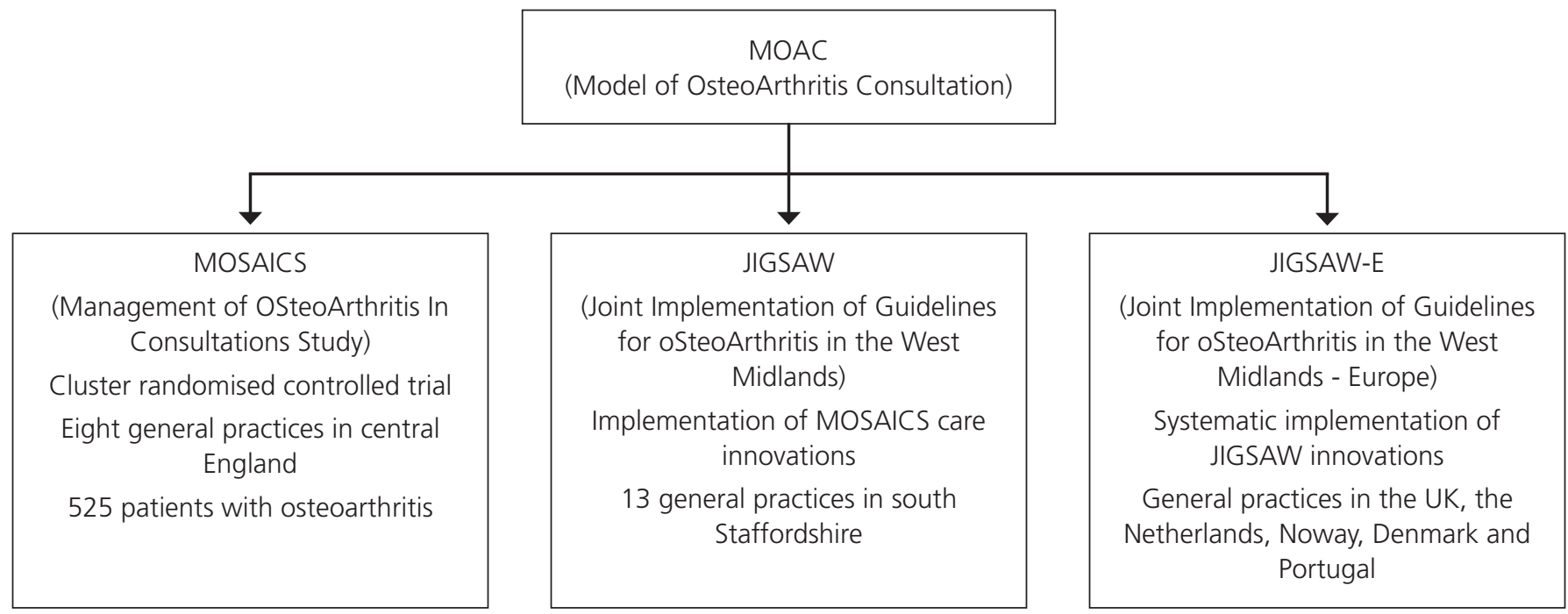

Porcheret et al., 2018). Furthermore, GPs believed that closing a consultation with the "OA booklet" and referral to a health professional led to improved patient satisfaction (Morden et al., 2014). Nurses' adherence to the NICE guidelines was also improved after the MOAC training, with nurses reporting increased confidence in managing people with OA and less need to refer back to the GP (Morden et al., 2015). People with OA reported having a clearer understanding of the cause, prognosis, and treatment of OA, and appreciation for receiving personalised advice (Morden et al., 2014). Additionally, they reported feeling that their condition was "legitimised" (Morden et al., 2014). Overall, GPs, nurses, and people with OA reported an improved ability to manage the condition (Morden et al., 2014).

\section{COULD THE MOAC IMPROVE PRIMARY CARE MANAGEMENT OF OA IN NEW ZEALAND?}

Given that the healthcare systems in New Zealand and the UK share some similarities (e.g., most primary care is GP based, and much of the secondary and tertiary care is publicly funded and hospital based), the successful implementation of the MOAC in the UK suggests there is scope to pilot the MOAC in New Zealand. Like the UK, people with OA in New Zealand tend to present to GP clinics as their primary management providers (Jolly et al., 2017, Larmer et al., 2019). This implementation strategy would likely facilitate shared care for OA between GPs and other primary care professionals, consistent with clinical guidelines that recommend an inter-professional management 
approach for OA. Implementation of the MOAC in New Zealand, focusing on the core treatments (education, exercise, and weight loss) delivered through primary care could alleviate the pressure on secondary and tertiary care by preventing or delaying the need for joint replacement surgery. However, formal evaluation of the cost-effectiveness of the MOAC is necessary.

\section{NEXT STEPS}

Based on the evidence reviewed, it seems feasible that the MOAC could be implemented in New Zealand, following in the footsteps of the MOSAICS, JIGSAW, and JIGSAW-E projects. The next step would be to pilot a MOAC programme in New Zealand. Implementation of a pilot MOAC in New Zealand would need to align with the 2016 Health Strategy, involve key stakeholders, and consider local structures and resources (Ministry of Health, 2016). In each country where the MOAC has been piloted, the programme has been adapted to match the needs of the population and health context. Should the MOAC be piloted in New Zealand, a similar adaptation process would be needed to ensure that it is culturally responsive and reduces the inequity of care for people living with $\mathrm{OA}$. This adaption process would require significant, meaningful input from key stakeholders, such as (but not limited to) iwi, Arthritis New Zealand, Primary Health Organisations, District Health Boards, the New Zealand College of GPs, and Physiotherapy New Zealand. Ongoing data collection and evaluation would need to be embedded in the design of a pilot MOAC to clarify improvements in service quality. However, a framework already exists that can be used to critically evaluate outcomes from the model of care (Briggs et al., 2016). This process should include a patient reported outcome measure capturing the quality of care for OA in accordance with clinical guidelines (Østerås et al., 2013). If the pilot was successful, specific policy would be needed to support the scale up of the MOAC (Allen, Choong, et al., 2016).

Physiotherapists are ideally placed to lead the implementation of a pilot MOAC in New Zealand. Physiotherapists can manage many people with musculoskeletal conditions in the primary care setting, and patients have high confidence in information, assessment and management provided by physiotherapists (Desmeules et al., 2012; Ludvigsson \& Enthoven, 2012). Physiotherapy-led OA programmes have resulted in improved patient outcomes (in terms of pain, function, and weight loss) as well as reducing the need for GP visits and the demand for joint replacement surgery (Claes et al., 2015; Deslauriers et al., 2017; Dziedzic et al., 2018; Hay et al., 2006; Ludvigsson \& Enthoven, 2012; Svege et al., 2015; Teoh et al., 2017). Currently, physiotherapists in Australia and Sweden are involved as primary care leaders in models of care for people with OA (Hunter et al., 2018; Jönsson et al., 2019). Similarly, physiotherapists in New Zealand could work closely with GPs as part of a multidisciplinary team to coordinate and improve care for people with OA.

\section{KEY POINTS}

What is already known?

1. Osteoarthritis $(O A)$ is a prevalent and costly condition.

2. In New Zealand, management of OA in primary care is fragmented and no clear implementation strategy exists that translates guidelines into clinical practice.

What this paper adds

3. This article makes a case for piloting the Model OsteoArthritis Consultation in New Zealand as an implementation strategy to optimise primary care management of $\mathrm{OA}$.

\section{DISCLOSURES}

No funding was received. There are no conflicts of interest which may be perceived to interfere with or bias this study.

\section{PERMISSIONS}

None.

\section{ACKNOWLEDGEMENTS}

The primary author would like to acknowledge Arthritis New Zealand and Auckland University of Technology, for ongoing support with this research.

\section{ADDRESS FOR CORRESPONDENCE}

Dr. Daniel O'Brien, Physiotherapy Department, School of Clinical Sciences, Auckland University of Technology, Auckland, 0627, New Zealand.

Email: dobrien@aut.ac.nz

\section{REFERENCES}

Abbott, J. H., Ward, A. L., Crane, C., Chapple, C. M., Stout, K., Hutton, L., Martin, V., Harcombe, H., Ribeiro, D. C., \& Gwynne Jones, D. (2019). Implementation of a 'Joint Clinic' to resolve unmet need for orthopaedic services in patients with hip and knee osteoarthritis: A program evaluation. BMC Musculoskeletal Disorders, 20(1), 324 (2019). https://doi. org/10.1186/s12891-019-2702-1

Accident Compensation Corporation/Te Kaporeihana āwhina Hunga Whara (2020). Here for New Zealand: ACC Annual Report-Purongo-a-tau 2020. https://www.acc.co.nz/assets/corporate-documents/annual-report-2020acc8234.pdf

Allen, K. D., Bongiorni, D., Bosworth, H. B., Coffman, C. J., Datta, S. K., Edelman, D., Hall, K. S., Lindquist, J. H., Oddone, E. Z., \& Hoenig, H. (2016). Group versus individual physical therapy for veterans with knee osteoarthritis: Randomized clinical trial. Physical Therapy, 96(5), 597-608. https://doi.org/10.2522/ptj.20150194

Allen, K. D., Choong, P. F., Davis, A. M., Dowsey, M. M., Dziedzic, K. S. Emery, C., Hunter, D. J., Losina, E., Page, A. E., Roos, E. M., Skou, S. T., Thorstensson, C. A., van der Esch, M., \& Whittaker, J. L. (2016). Osteoarthritis: Models for appropriate care across the disease continuum Best Practice \& Research Clinical Rheumatology, 30(3), 503-535. https:// doi.org/10.1016/j.berh.2016.09.003

Arthritis New Zealand. (2018). The Economic Cost of Arthritis in New Zealand in 2018. https://www.arthritis.org.nz/wp-content/uploads/2018/09/ Economic-cost-of-Arthritis-in-New-Zealand-2018.pdf

Baldwin, J., Briggs, A. M., Bagg, W., \& Larmer, P. J. (2017). An osteoarthritis model of care should be a national priority for New Zealand. New Zealand Medical Journal, 130(1467), 78-86. 
Brand, C., Hunter, D., Hinman, R., March, L., Osborne, R., \& Bennell, K. (2011). Improving care for people with osteoarthritis of the hip and knee: How has national policy for osteoarthritis been translated into service models in Australia? International Journal of Rheumatic Diseases, 14(2), 181-190. https://doi.org/10.1111/j.1756-185X.2011.01613.x

Briggs, A. M., Jordan, J. E., Jennings, M., Speerin, R., Bragge, P., Chua, J., Woolf, A. D., \& Slater, H. (2016). Supporting the evaluation and implementation of musculoskeletal models of care: A globally-informed framework for judging 'readiness' and 'success'. Arthritis Care \& Research, 69(4), 567-577. https://doi.org/10.1002/acr.22948

Briggs, A. M., Towler, S. C. B., Speerin, R., \& March, L. M. (2014). Models of care for musculoskeletal health in Australia: Now more than ever to drive evidence into health policy and practice. Australian Health Review, 38(4), 401-405. https://doi.org/10.1071/AH14032

Claes, B.-E. A., Leung, H. W. C., Matters, K., Williams, M. J., \& Hunter, D. J. (2015). Interim analysis: An interdisciplinary team approach in facilitating weight reduction and improving function for people with knee or hip osteoarthritis. The Osteoarthritis Chronic Care Program at Royal North Shore Hospital. Nutrition \& Dietetics, 72(3), 232-239. https://doi. org/10.1111/1747-0080.12166

Conaghan, P. G., Dickson, J., Grant, R. L., on behalf of the Guideline Development Group. (2008). Care and management of osteoarthritis in adults: Summary of NICE guidance. BMJ, 336(7642), 502. https://doi. org/10.1136/bmj.39490.608009.AD

Deslauriers, S., Toutant, M.-E., Lacasse, M., Desmeules, F., \& Perreault, K. (2017). Integrating physiotherapists into publicly funded primary care: A call to action. Physiotherapy Canada, 69(4), 275-276. https://doi. org/10.3138/ptc.69.4.GEE

Desmeules, F., Roy, J.-S., MacDermid, J. C., Champagne, F., Hinse, O., \& Woodhouse, L. J. (2012). Advanced practice physiotherapy in patients with musculoskeletal disorders: A systematic review. BMC Musculoskeletal Disorders, 13, 107. https://doi.org/10.1186/1471-2474-13-107

Dziedzic, K. S., Healey, E. L., Porcheret, M., Afolabi, E. K., Lewis, M., Morden, A., Jinks, C., McHugh, G. A., Ryan, S., Finney, A., Main, C., Edwards, J. J., Paskins, Z., Pushpa-Rajah, A., \& Hay, E. M. (2018). Implementing core NICE guidelines for osteoarthritis in primary care with a model consultation (MOSAICS): A cluster randomised controlled trial. Osteoarthritis and Cartilage, 26(1), 43-53. https://doi.org/10.1016/j.joca.2017.09.010

Goddard-Nash, A., Makate, M., Varhol, R., Quirk, F., Larsen, R., McGeoch, G., Shand, B., \& Robinson, S. (2020). Evaluation of HealthPathways: An appraisal of usage, experiences and opinions of healthcare professionals in Australia and New Zealand. Australian Health Review, 44(4), 590-600. https://doi.org/10.1071/AH19214

Hay, E. M., Foster, N. E., Thomas, E., Peat, G., Phelan, M., Yates, H. E., Blenkinsopp, A., \& Sim, J. (2006). Effectiveness of community physiotherapy and enhanced pharmacy review for knee pain in people aged over 55 presenting to primary care: Pragmatic randomised trial. BMJ, 333(7576), 995. https://doi.org/10.1136/bmj.38977.590752.0B

Healey, E. L., Afolabi, E. K., Lewis, M., Edwards, J. J., Jordan, K. P., Finney, A., Jinks, C., Hay, E. M., \& Dziedzic, K. S. (2018). Uptake of the NICE osteoarthritis guidelines in primary care: A survey of older adults with joint pain. BMC Musculoskeletal Disorders, 19(1), 295. https://doi.org/10.1186/ s12891-018-2196-2

Hooper, G., Lee, A., Rothwell, A., \& Frampton, C. (2014). Current trends and projections in the utilisation rates of hip and knee replacement in New Zealand from 2001 to 2026. The New Zealand Medical Journal, 127(1401), 82-93.

Hunter, D. J. (2011). Lower extremity osteoarthritis management needs a paradigm shift. British Journal of Sports Medicine, 45(4), 283-288. https:// doi.org/10.1136/bjsm.2010.081117

Hunter, D. J. (2017). Osteoarthritis management: Time to change the deck. Journal of Orthopaedic and Sports Physical Therapy, 47(6), 370-372. https://doi.org/10.2519/jospt.2017.0605
Hunter, D. J., Hinman, R. S., Bowden, J. L., Egerton, T., Briggs, A. M., Bunker, S. J., Kasza, J., Forbes, A. B., French, S. D., Pirotta, M., Schofield, D. J., Zwar, N. A., Bennell, K. L., \& the PARTNER Study Team. (2018). Effectiveness of a new model of primary care management on knee pain and function in patients with knee osteoarthritis: Protocol for the PARTNER study. BMC Musculoskeletal Disorders, 19, 132. https://doi.org/10.1186/ s12891-018-2048-0

James, S. L., Abate, D., Abate, K. H., Abay, S. M., Abbafati, C., Abbasi, N. Abbastabar, H., Abd-Allah, F., Abdela, J., Abdelalim, A., Abdollahpour, I., Abdulkader, R. S., Abebe, Z., Abera, S. F., Abil, O. Z., Abraha, H. N., AbuRaddad, L. J., Abu-Rmeileh, N. M. E., Accrombessi, M. M. K., ... Murray, C. J. L. (2018). Global, regional, and national incidence, prevalence, and years lived with disability for 354 diseases and injuries for 195 countries and territories, 1990-2017: A systematic analysis for the Global Burden of Disease Study 2017. The Lancet, 392(10159), 1789-1858. https://doi. org/10.1016/S0140-6736(18)32279-7

Jolly, J. J., Bassett, S. F., O'Brien, D., Parkinson, C., \& Larmer, P. J. (2017). An exploration of the sequence and nature of treatment options available to people living with osteoarthritis of the hip and/or knee within a New Zealand context. New Zealand Journal of Physiotherapy, 45(2), 90-95. https://pnz.org.nz/Folder?Action=View\%20File\&Folder_id=617\&File=jolly. pdf

Jönsson, T., Eek, F., Dell'Isola, A., Dahlberg, L. E., \& Hansson, E. E. (2019). The Better Management of Patients with Osteoarthritis Program: Outcomes after evidence-based education and exercise delivered nationwide in Sweden. PLOS ONE, 14(9), e0222657. https://doi.org/10.1371/journal. pone. 0222657

Jordan, K. P., Edwards, J. J., Porcheret, M., Healey, E. L., Jinks, C., Bedson J., Clarkson, K., Hay, E. M., \& Dziedzic, K. S. (2017). Effect of a model consultation informed by guidelines on recorded quality of care of osteoarthritis (MOSAICS): A cluster randomised controlled trial in primary care. Osteoarthritis and Cartilage, 25(10), 1588-1597. https://doi. org/10.1016/j.joca.2017.05.017

Keele University. (n.d.). JIGSAW-E. Keele University. Retrieved November 22, 2018, from https://www.keele.ac.uk/pchs/implementingourresearch/ makinganimpact/osteoarthritisandosteoporosis/jigsaw/

Larmer, P. J., Bennett, K, Baldwin, J. N., Bassett, S.F., \& O’Brien, D. W. (2019). Quality indicators for hip and knee osteoarthritis in New Zealand: A patient survey. New Zealand Journal of Physiotherapy, 47(3), 183-192. https://doi.org/10.15619/NZJP/47.3.06

Ludvigsson, M. L., \& Enthoven, P. (2012). Evaluation of physiotherapists as primary assessors of patients with musculoskeletal disorders seeking primary health care. Physiotherapy, 98(2), 131-137. https://doi. org/10.1016/j.physio.2011.04.354

McGeoch, G., McGeoch, P., \& Shand, B. (2015). Is HealthPathways effective? An online survey of hospital clinicians, general practitioners and practice nurses. The New Zealand Medical Journal, 128(1408), 36-46.

Ministry of Health. (2016). New Zealand health strategy: Future direction. https://www.health.govt.nz/system/files/documents/publications/newzealand-health-strategy-futuredirection-2016-apr16.pdf

Ministry of Health. (2017). Annual data explorer 2016/17: New Zealand health survey. https://minhealthnz.shinyapps.io/nz-health-survey-2018-19annual-data-explorer/_w_77073a60/\#!/home

Ministry of Health. (2019). The Mobility Action Programme. https://www. health.govt.NZ/our-work/preventative-health-wellness/mobility-actionprogramme

Morden, A., Brooks, L., Jinks, C., Porcheret, M., Ong, B. N., \& Dziedzic, K. (2015). Research "push", long term-change, and general practice. Journal of Health Organization and Management, 29(7), 798-821. https://doi. org/10.1108/JHOM-07-2014-0119

Morden, A., Jinks, C., Ong, B. N., Porcheret, M., \& Dziedzic, K. S. (2014). Acceptability of a 'guidebook' for the management of osteoarthritis: A qualitative study of patient and clinician's perspectives. BMC Musculoskeletal Disorders, 15(1), 427. https://doi.org/10.1186/14712474-15-427 
National Institute for Health and Care Excellence. (2021). Osteoarthritis. Quality standard (June, 2015). https://www.nice.org.uk/guidance/qs87/ resources/osteoarthritis-pdf-2098913613253

Østerås, N., Garratt, A., Grotle, M., Natvig, B., Kjeken, I., Kvien, T. K., \& Hagen, K. B. (2013). Patient-reported quality of care for osteoarthritis: Development and testing of the OsteoArthritis Quality Indicator Questionnaire. Arthritis Care \& Research, 65(7), 1043-1051. https://doi. org/10.1002/acr.21976

Poitras, S., Rossignol, M., Avouac, J., Avouac, B., Cedraschi, C., Nordin, M., Rousseaux, C., Rozenberg, S., Savarieau, B., Thoumie, P., Valat, J.-P., Vignon, E., \& Hilliquin, P. (2010). Management recommendations for knee osteoarthritis: How usable are they? Joint, Bone, Spine, 77(5), 458-465. https://doi.org/10.1016/j.jbspin.2010.08.001

Porcheret, M., Grime, J., Main, C., \& Dziedzic, K. (2013). Developing a model osteoarthritis consultation: A Delphi consensus exercise. BMC Musculoskeletal Disorders, 14(1), 25. https://doi.org/10.1186/1471-2474$14-25$

Porcheret, M., Main, C., Croft, P., \& Dziedzic, K. (2018). Enhancing delivery of osteoarthritis care in the general practice consultation: Evaluation of a behaviour change intervention. BMC Family Practice, 19(1), 26. https://doi. org/10.1186/s12875-018-0715-8
Quicke, J.G., Somerville, S., Oxtoby, J., Wallbanks, A., Campbell, L., Blackburn, S., Stevenson, K., Cooper, V., Finney A., Wathall, S., Edwards, J. J., Evans, N., \& Dziedzic, K. (2019). Implementing and evaluating a pilot physiotherapist-led osteoarthritis clinic in general practice. Physiotherapy, 105(Supplement 1), E33-E34. https://doi.org/10.1016/j. physio.2018.11.278

Reid, D., Potts, G., Burnett, M., \& Konings. (2014). Physiotherapy management of knee and hip osteoarthritis: A survey of patient and medical practitioners' expectations, experiences and perceptions of effectiveness of treatment. New Zealand Journal of Physiotherapy, 42(3), $118-125$

Svege, I., Nordsletten, L., Fernandes, L., \& Risberg, M. A. (2015). Exercise therapy may postpone total hip replacement surgery in patients with hip osteoarthritis: A long-term follow-up of a randomised trial. Annals of the Rheumatic Diseases, 74(1), 164-169. https://doi.org/10.1136/ annrheumdis-2013-203628

Teoh, L. S. G., Eyles, J. P., Makovey, J., Williams, M., Kwoh, C. K. \& Hunter, D. (2017). Observational study of the impact of an individualized multidisciplinary chronic care program for hip and knee osteoarthritis treatment on willingness for surgery. International Journal of Rheumatic Diseases, 20(10), 1383-1392. https://doi.org/10.1111/1756-185X.12950

Wilson, R., \& Abbott, J. H. (2019). The projected burden of knee osteoarthritis in New Zealand: Healthcare expenditure and total joint replacement provision. The New Zealand Medical Journal, 132(1503), 53-65. 